\title{
Statistics of the Seismic Sequence and Rupture Directivity of the M5.5 Earthquake in Orkney, South Africa
}

\author{
Carsten Dinske ${ }^{1}$, Jonas Folesky ${ }^{1}$, Jörn Kummerow ${ }^{1}$, Serge Shapiro ${ }^{1}$, and Hiroshi Ogasawara ${ }^{2}$ \\ ${ }^{1}$ Freie Universität Berlin, Department of Earth Sciences, Geophysics, Berlin, Germany \\ ${ }^{2}$ Ritsumeikan University, College of Science and Engineering, Kusatsu, Japan
}

Correspondence: Carsten Dinske (carsten[at]geophysik.fu-berlin.de)

\begin{abstract}
Despite our general knowledge of earthquake processes, it is still not fully understood how earthquake ruptures nucleate and propagate and why they stop. Also, the controlling factors of the frequency and of the size of earthquakes are subject of ongoing research. We aim to address these questions with a comprehensive study of seismicity in deep South African gold mines. We find here the unique situation that the seismicity consists of both induced earthquakes and aftershocks triggered

5 by the M5.5 Orkney earthquake which occurred in August 2014. We separate the cataloged seismicity and group the events into three classes: the aftershock sequence, seismicity induced by fluids, and seismicity induced by mining activities. We examine statistical properties of earthquakes in each of the three classes. We conclude that the magnitude statistics of both aftershocks and induced earthquakes are influenced by the finite size and geometry of the rock volume of stress perturbation resulting in an absence of larger magnitude events. The magnitude frequency distributions obey the Lower Bound model of magnitude probability. The statistics of dynamic stress drop of aftershocks and induced earthquakes satisfy log-normal distributions but the value range is different, it means that aftershocks are generally characterized by higher stress drops. Another key aspect in our study is the imaging of the propagating rupture of the M5.5 earthquake. We apply the back projection imaging approach using seismological data from two different local networks and retrieve similar results. We conclude that the rupture of the M5.5 earthquake propagated predominantly unilaterally, nearly from North to South over a distance of about $6 \mathrm{~km}$. The hypocenters of the aftershock sequence are situated unilaterally in respect to the hypocenter of the main shock and are aligned to the South which confirms the obtained rupture propagation image and the directivity of the main shock.
\end{abstract}

\section{Introduction}

On 5 August 2014, an earthquake with local magnitude M5.5 occurred beneath the Moab Khotsong gold mine in Orkney which is located $150 \mathrm{~km}$ southwest of Johannesburg in South Africa. The Orkney earthquake was the second largest recorded seismic event in South Africa and the largest within an active mining area (Manzunzu et al., 2017). South Africa is generally regarded as a stable continental region (SCR) with a rare number of earthquakes exceeding magnitude 4.5. The majority of the seismicity observed in active mine districts is induced by mining operations and the largest earthquakes have been recorded with magnitudes around M4 (Richardson and Jordan, 2002). Hence the occurrence of the Orkney earthquake in this intraplate continental context is atypical leaving room for speculations about its nature (Manzunzu et al., 2017). The earthquake was 
https://doi.org/10.5194/se-2020-58

Preprint. Discussion started: 12 May 2020

(c) Author(s) 2020. CC BY 4.0 License.

(c) (i)

atypical also because it was a sinistral strike slip event on an unknown geological structure below the mine whereas the seismicity in the mining horizons are typically normal faulting events.

Earthquakes induced by activities and operations in deep-level mines are a topic of research since decades starting with the pioneering works of Spottiswoode and McGarr (1975) and Gay and Ortlepp (1979). In the 1990, seismic monitoring and quantitative seismic hazard assessment became routine work in South African gold mines (Mendecki, 1996; Mendecki et al., 1999; Van Aswegen et al., 2005). Substantial progress in the understanding of mining-induced earthquakes was achieved within the last decade mainly by the JAGUARS (Japanese German Acoustic Emission Research in South Africa) and the SATREPS (Science and Technology Research Partnership for Sustainable Development) projects (see e.g. Nakatani et al., 2008; Yabe et al., 2009; Moriya et al., 2015; Naoi et al., 2011, 2015; Ziegler et al., 2015). Highly sensitive acoustic emission sensors were additionally deployed in the gold mines. This enabled analysis of scaling laws of events occurring in deep mines and the verification that scaling relations involving event size, rupture dimension and earthquake stress drop retain their validity also in case of extremely small, high-frequency acoustic emission (AE) events (Boettcher et al., 2009; Kwiatek et al., 2010, 2011; Naoi et al., 2014). It was also concluded that the combined analysis of different types of earthquakes in mining environment including aftershocks leads to unusual shape and curvature of the magnitude frequency distribution (Boettcher et al., 2009). Naoi et al. (2014) argued that the size distributions of seismic events occurring in the vicinity of mining fronts follow a Gutenberg-Richter law but with minor variations of the $b$ value with time. The monitoring of $\mathrm{AE}$ also allowed to study the nucleation process of a M2.2 earthquake in a deep mine in South Africa documented by Yabe et al. (2015). The authors concluded that the earthquake ruptured a preexisting plane of weakness and the AE activity during six month prior to the main shock already delineated the rupture plane in advance.

In August 2016, the International Continental Drilling Programme (ICDP) has approved drilling into M2.0-M5.5 seismogenic zones from deep gold mines in South Africa (DSeis). The drilling project aims to probe quasi-static and dynamic ruptures, to recover cores fully, to measure stress, and to log boreholes and cores (Voosen, 2017). Several holes have been successfully drilled and the last drilling was completed in June 2018. The targets also included the seismogenic zone of the Orkney earthquake (Figure 1).

Here, we present our results of a comprehensive study of the seismicity observed in the Orkney area. It includes not only the aftershock sequence of the M5.5 earthquake but also induced earthquakes due to mining operations. Essentially, we study the magnitude statistics of the different classes of seismicity in order to identify characteristic patterns that might be supportive in hazard assessment and mitigation. Additionally, we establish a rough connection between the area of aftershock activity and the area of stress perturbation of the M5.5 earthquake using the back projection imaging technique for tracking the propagating rupture of this earthquake.

Recently, a more comprehensive earthquake catalog compared to the initial catalog was compiled and provided by Anglogold Ashanti (Pty) Ltd. The Anglogold Ashanti in-mine routine seismic monitoring systems have been in operation since 1990s, with several tens of underground stations at 2-3 km depth, in the deepest levels of Moab Khotsong, Great Noligwa and Kopanang gold mines. The new catalog covers the time period from August 2014 to September 2017. It contains approximately 70,000 earthquakes which can be subdivided into three classes. These are (1) the aftershock sequence with about 15,000 earthquakes, 
https://doi.org/10.5194/se-2020-58

Preprint. Discussion started: 12 May 2020

(c) Author(s) 2020. CC BY 4.0 License.

(c) (i)

60 (2) mining induced seismicity with about 7,000 earthquakes, and (3) fluid induced seismicity with nearly 48,000 earthquakes. Figure 2 shows the hypocenter locations of the three classes of earthquakes.

\section{Magnitude statistics of the M5.5 aftershock sequence}

First, we study the statistics of magnitudes of the aftershock sequence which we educe from the whole catalog. The sequence contains approximately 15,000 events and their hypocenter locations are shown in Figure 3. The area of aftershock activity extends over $5 \mathrm{~km}$ in NNW-SSE direction, $0.5 \mathrm{~km}$ perpendicular to the strike direction and $1.5 \mathrm{~km}$ in vertical direction dipping to the South. The M5.5 main shock is situated at the northern edge of the aftershock cloud. The locations of aftershocks with respect to the main shock location raises the speculation that the rupture of the main shock propagated unilaterally to the South. The magnitude frequency distribution of the aftershock sequence illustrated in Figure 4(a). We estimate the b-value of the Gutenberg-Richter law (Gutenberg and Richter, 1944) using the maximum likelihood method introduced by Utsu (1966) and later modified by Bender (1983). The corresponding graph atop the observed magnitude distribution reveales that the number of aftershocks with a magnitude $M>1.5$ deviates from the strict power law of the Gutenberg-Richter relation. Such a phenomenon is often observed for the magnitude frequency distribution of fluid induced seismicity where the seismically active rock volume is restricted to the domain of pore pressure perturbation (Shapiro et al., 2011, 2013; Shapiro, 2015). A finite perturbed rock volume influences the magnitude statistics of fluid induced earthquakes. Here, we find similarly for the M5.5 aftershock sequence. The occurrence of aftershocks is restricted in space to the domain of stress perturbation caused by the preceding main shock. This leads to a finite size and to a nearly fixed geometry of the seismically active rock volume which influences correspondingly the magnitude statistics of the aftershock sequence. Therefore, we apply the so-called Lower Bound model of the magnitude probability (Shapiro et al., 2013), which captures the effect of a finite perturbed rock volume on the magnitude statistics, to the Orkney aftershock sequence. We conclude that the lower bound model represents a better approximation to the observed magnitude frequency distribution as shown in Figure 4(b)). Furthermore, with the application of the Lower Bound model we retrieve a geometry-corrected estimate of the b-value of the magnitude frequencies of aftershocks which we report in Table 1. Note, that the difference in b-value is marginal only but it influences seismic hazard assessment. The Lower Bound model yields also an estimate of the maximum possible magnitude of an earthquake occurring within the spatially confined rock volume of a stress perturbation. In the present case of the aftershock sequence of the Orkney earthquake, the maximum possible magnitude of an aftershock is estimated to be $M_{\max }=2.4$. This agrees with the observation, however, it contradicts Båth law (Båth and Duda, 1964; Båth, 1981) which empirically states that the magnitude of the largest aftershock is around one order lower than the nagnitude of the preceding main shock. Additionally, the lower bound model provides an alternative way to derive the stress drop $\Delta \sigma$ (Shapiro et al., 2013). This parameter is an averaged representation for the aftershock sequence and it is also reported in Table 1.

90 Now, we compare the statistical characteristics of magnitudes of the aftershock sequence to other seismicity observed in the gold mines in the Orkney area. These are two different types of earthquakes caused by human operations, either induced by fluid or induced by mining, respectively. Figure 5 depicts the corresponding magnitude frequency distributions as well as the 
https://doi.org/10.5194/se-2020-58

Preprint. Discussion started: 12 May 2020

(c) Author(s) 2020. CC BY 4.0 License.

(c) (i)

Gutenberg-Richter law using maximum likelihood b-value estimates. The magnitude frequency distributions are influenced in such way that larger magnitudes are under-represented in comparison to the power-law of the Gutenberg-Richter relation. It reflects again the influence of a finite perturbed rock volume on the magnitude statistics. We find that this influence is more pronounced for mining induced seismicity. We apply the Lower Bound model of magnnitude probabilities to the magnitude frequency distributions of induced earthquakes (Figure 6) which result in geometry-corrected estimates of the GutenbergRichter $b$-value and the maximum possible magnitude, and in estimates of averaged stress drop $\Delta \sigma$ (Table 1). Fluid induced and mining induced events differ clearly regarding the statistics of magnitudes. We obtain with the Lower Bound model the highest b-value and lowest stress drop estimates for fluid induced seismicity. In contrast, mining induced seismicity is characterized by the lowest $b$-value resulting therefore in a higher estimate of the maximum possible magnitude.

We also compare the statistics of stress drops for the three different classes of seismicity (Figure 7). We find it remarkable that stress drops are similar distributed, precisely log-normal distributions, independent of the event type. However, the value ranges are different, it means the stress drop of aftershocks is approximately two orders of magnitude higher than the stress drop of induced earthquakes. We observe the lowest stress drop values for the seismicity that is induced by fluid. Finally, we analyze how the cataloged earthquake stress drops relate to the averaged stress drop estimate resulting from the Lower Bound model. The median values of static and dynamic stress drops are summarized in Table 1 and we find that the Lower Bound derived stress drops are reasonable values and are in good agreement with the median of dynamic stress drops. This finding holds for all three classes of seismicity.

\section{Imaging the M5.5 rupture}

There exist few methods to track the propagation and the directivity of earthquakes ruptures including the back projection imaging technique. We apply the Microseismic Rupture Propagation Imaging (MRPI) technique (Folesky et al., 2015) to the Orkney earthquake. The method is based on the back-projection technique (Ishii et al., 2005; Krüger and Ohrnberger, 2005) but was modified to cope with the special conditions imposed by local seismic networks. For tracking the rupture propagation, we back-project the recorded wavefield to a grid of possible source locations. Mathematically, we stack the absolute values of Pwave amplitudes of displacement seismograms recorded at a selected number of stations as functions of time for every potential source grid point corrected by the predicted theoretical source-receiver traveltime (Ishii et al., 2007). Theoretical traveltimes are obtained from the finite difference eikonal solver of Podvin and Lecomte (1991) which is implemented in the NonLinLoc software (Lomax, 2011). NonLinLoc is also used to calculate hypocenter location, origin time, and traveltime residuals. The residuals are used to shift the P-wave amplitude traces to account for velocity model uncertainties. Our results of the inversion for hypocenter location and origin time differ from results previously known from other sources (CGS, Manzunzu et al. (2017), and Moyer et al. (2017)). However, the computed traveltimes for the relocated earthquake hypocenter are now more consistent with the observation and a consistent traveltime-grid is needed for the application of MRPI.

At first, we use the main shock registrations at stations installed in the deep mines. The networks are operated by Anglogold Ashanti (Pty) Ltd (AGA) using a seismic monitoring system commercially available from the Institute of Mine Seismology 
https://doi.org/10.5194/se-2020-58

Preprint. Discussion started: 12 May 2020

(c) Author(s) 2020. CC BY 4.0 License.

(c) (i)

(Pty) Ltd (IMS) which is specialized in seismic monitoring of industrial underground activities (Mendecki, 1996). Highquality waveform data with good signal-to-noise ratios were recorded at $4.5 \mathrm{~Hz} 3$-component geophones with a sampling rate of $6000 \mathrm{~Hz}$. Figure 8 shows the spatial distribution of stations of the three in-mine networks and the cut-out P-waveforms which we use in the MRPI method. To invert for the hypocenter location and to compute the traveltime-grid, we apply a homogeneous 1-layer velocity model with $v_{P}=5.89 \mathrm{~km} / \mathrm{s}$ and $v_{S}=3.69 \mathrm{~km} / \mathrm{s}$ for P-wave and S-wave,respectively, that was provided by AGA and IMS.

The results of the MRPI method for wavefields from the in-mine stations are illustrated in Figure 9, for one image we use absolute values of P-wave amplitudes and for the other image the envelopes. Both show the maximum of stacked back-projected energy in space and time providing a track of the rupture propagation. The rupture approximately propagated unilaterally from $\mathrm{N}$ to SSW in the beginning (bluish colors) and then continues in S direction (greenish and yellowish colors). At the end of the rupture track (reddish colors), we observe a lot of scatter which correlates with an amplitude decrease of the energy stack value and it indicates the end of the rupture process.

Comparing the rupture track with the spatial distribution of aftershocks, we find that the elongation of the aftershock cloud in N-S direction fits well the rupture length. But, the aftershock cloud is shifted southwards by one to two kilometers which we identify by comparing Figures 9 and 10(a). Also, the strike directions of both the cloud and the rupture track are slightly different. One reason for this finding could be the spatial distribution of stations of the in-mine network which is suboptimal because of the limited azimuthal coverage with respect to the earthquake location (Figure 8(a)). However, Manzunzu et al. (2017) determined focal mechanisms for the M5.5 earthquake and a selected number of aftershocks (Figure 10(b)). They found that the main shock occurred on a steeply dipping strike-slip fault with a strike direction of $182.6^{\circ} \mathrm{N}$. The strike direction of the rupture track coincides in a first approximation with the reported focal mechanism.

Additionally, we also apply the back projection imaging using wavefields recorded at the surface network. Figure 11 shows the spatial distribution of stations of this network which is operated by the Council for Geoscience South Africa (CGS) and cut-out recordings of P-waveforms that we use for the MRPI. The azimuthal coverage of the station distribution is slightly enhanced in comparison to the in-mine network but still not perfect. The network is equiped mainly with 3-components broadband seismometers, data are recorded with $200 \mathrm{~Hz}$ sample rate. Since we consider here the surface network, we apply a more advanced but still rather simple velocity model which is listed in Table 2. It consists of two layers with homogeneous velocities and it was build based on input from AGA and Moyer et al. (2017).

The resulting energy stack images are illustrated in Figures 12. Interestingly, by ignoring the scatter points at the beginning and at the end, we observe that the rupture nucleates around our determined earthquake hypocenter and propagates first in Northwest direction for about $2 \mathrm{~km}$ where it turns and then propagates to the South. Such an observed complexity of rupture behavior indicating an initial and a main rupture phase was also reported by Ellsworth (pers. communication). He carried out a slip inversion for the M5.5 earthquake on a vertical plane and he found that the initial rupture origin is located to the South of the main rupture origin which propagated mainly southward. 
https://doi.org/10.5194/se-2020-58

Preprint. Discussion started: 12 May 2020

(c) Author(s) 2020. CC BY 4.0 License.

(c) (i)

\section{Discussion and Conclusions}

The combination of three sources of earthquake data - waveform recordings from a surface network, from a deep in-mine network, and a comprehensive catalog with about 70,000 earthquakes - allowed for detailed investigations of seismogenic processes in a spatially confined, seismically active volume. We separated the cataloged seismicity and grouped the events into three different classes: $(1)$ the aftershock sequence of the Orkney M5.5 earthquake ( $\approx 15,000 \mathrm{EQ})$, (2) seismicity induced by fluids $(\approx 48,000 \mathrm{EQ})$, and $(3)$ seismicity induced by mining activity $(\approx 7,000 \mathrm{EQ})$. We studied statistical properties of earthquakes in each of the three classes and compared jointly the results. We focused on the magnitude statistics and on the statistics of dynamic stress drop. Another key aspect in our study was the imaging of the propagating rupture of the M5.5 earthquake. We applied successfully the back-projection method using seismological recordings from two different, independently operating networks and retrieved comparable results.

We concluded that the rupture of the M5.5 earthquake propagated predominantly unilaterally, nearly from North to South over a distance of about $6 \mathrm{~km}$. In general, the coherency of waveforms is high for seismic networks located at teleseismic distances to the earthquake source which facilitates application of the back-projection imaging. In our case, however, the waveforms were recorded at spatially suboptimally distributed stations of local monitoring system. Hence the waveforms can be quite variable due to earthquake radiation pattern, higher frequencies and local heterogeneity of seismic velocities and attenuation structure. To avoid this complexity, there exists a different and simpler geometrical method, the P-wave polarization stacking (PPA), for imaging the propagating rupture front. The method was introduced by Bayer et al. (2012) and we recently applied it successfully to seismicity on a regional scale in N-Chile (Folesky et al., 2018a) and on a local scale in Italy (Folesky et al., 2018b). Wehner et al. (2018) tested the feasibility for the situation in Orkney and they concluded that the P-wave polarization stacking approach can be considered another method for tracking the rupture front of the M5.5 earthquake. The resulting final image of the rupture track revealed a southward propagation over a distance of about $4 \mathrm{~km}$ (Wehner, 2018). The images of back-projected seismic energy using the surface recordings indicated a complex rupture process of the Orkney earthquake. Two nucleation slip patches, an initial and a main rupture origin, appeared to locate on the rupture surface. They were seperated horizontally by around $2 \mathrm{~km}$ in which the initial origin is south of the main origin. An assimiable observation supporting our findings was reported by Moyer et al. (2017). They identified an immediate foreshock precursory to the main shock which was located in about $1.4 \mathrm{~km}$ horizontal distance south of the main shock. Integrating both observations supports the conclusion that the interaction of two patches led to the M5.5 Orkney earthquake. Such a phenomenon is well-studied for subduction zone earthquakes. It was discussed and concluded that interactions and synchronization between multiple patches along the subduction interface led to the $M_{w} 9.0$ Tohoku-oki earthquake in March 2011 (see Aochi and Ide, 2011; Hori and Miyazaki, 2011; Kiser and Ishii, 2012, e.g.). A similar complex triggering model was reported by Kiser and Ishii (2011) also for the $M_{w} 8.8$ Maule earthquake which occurred in 2010.

The hypocenters of the aftershock sequence of the M5.5 earthquake are situated unilaterally in respect to the hypocenter of the main shock and are aligned to the South. In general, this observation confirms the obtained rupture propagation image and the directivity of the main shock. Furthermore, the extent of the aftershock cloud in N-S direction is in agreement with the length 
https://doi.org/10.5194/se-2020-58

Preprint. Discussion started: 12 May 2020

(c) Author(s) 2020. CC BY 4.0 License.

(c) (i)

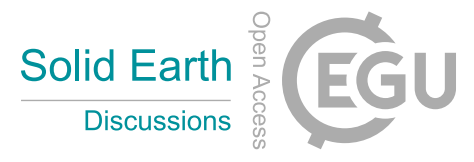

of the imaged rupture track even though the two are offset slightly. We found that the magnitude statistics of both aftershocks and induced earthquakes are affected by the finite size and geometry of the rock volume of stress perturbation which inhibits the occurrence of larger magnitude events. This influence is most pronounced for the magnitudes of aftershocks whereas it is least for fluid induced seismicity. The observed magnitude frequency distributions of aftershocks and induced earthquakes were fitted with the Lower Bound model of magnitude probabilities resulting in geometry-corrected b-values of the GutenbergRichter relation. The computed maximum possible magnitude of an earthquake occurring in given finite perturbed rock volume is in the case of aftershocks and mining induced seismicity significantly lower than an expected maximum magnitude based on a classical non-truncated power-law Gutenberg-Richter law. The statistics of stress drop of aftershocks as well as of induced earthquakes comply with a log-normal distribution but the value range is different, it means aftershocks are generally characterized by higher stress drops and seismicity induced by fluid shows the lowest stress drops. The averaged stress drops, estimated with the Lower Bound model, retain the ranking of the three different classes of seismicity. Interestingly, the Lower Bound stress drops are closer to the median of dynamic stress drops than to the median of static stress drops. Overall, our findings and conclusions have basically the potential to contribute to an improved assessment and a possible mitigation of seismic hazard in active mining districts. In particular, we think that the Lower Bound model combined either with the Omori-Utsu model for aftershock productivity or with a Poissonian model for induced earthquakes would be a first step towards more realistic hazard estimations of mining operations.

Code and data availability. Software codes in order to process and analyze the seismological data were written in MATLAB@®and are available upon request from the corresponding author. The seismological data from the CGS network are downloadable from the CGS webpage and are also available from the supplementary material of Moyer et al. (2017). The in-mine networks data used in this research (catalog as well as stations recordings) are not publicly available. The data were provided by AngloGold Ashanti Ltd. and Harmony Gold Ltd. based on a collaboration within the framw of the DSeis drilling project.

Author contributions. CD carried out the data analysis and wrote the manuscript. JF provided the imaging tools used in this study, and JF and JK assisted substantially in the interpretation of the obtained results. SS and HO are PI of the ICDP funded project DSeis - Drilling into Seismogenic Zones of M2.0-M5.5 Earthquakes in Deep South African Gold Mines.

Competing interests. The authors declare that they have no conflict of interest.

Acknowledgements. The research presented in this paper was funded by the German Research foundation, DFG, project numbers SH 55/16-1 and KU 2484/4-1. We thank all institutions that are involved with operating the AGA and CGS seismic monitoring networks and providing 
https://doi.org/10.5194/se-2020-58

Preprint. Discussion started: 12 May 2020

(C) Author(s) 2020. CC BY 4.0 License.

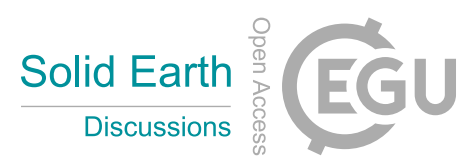

220 the earthquake data and additional information. We thank AngloGold Ashanti Ltd. and Harmony Gold Ltd. for the permission to publish this study. 
https://doi.org/10.5194/se-2020-58

Preprint. Discussion started: 12 May 2020

(c) Author(s) 2020. CC BY 4.0 License.

(c) (i)

\section{References}

Aochi, H. and Ide, S.: Conceptual multi-scale dynamic rupture model for the 2011 off the Pacific coast of Tohoku earthquake, Earth, Planets and Space, 63, 46, 2011.

Båth, M.: Earthquake magnitude — recent research and current trends, Earth-Science Reviews, 17, 315-398, 1981.

Båth, M. and Duda, S.: Earthquake volume, fault plane area, seismic energy, strain, deformation and related quantities, Annals of Geophysics, 17, 353-368, 1964.

Bayer, B., Kind, R., Hoffmann, M., Yuan, X., and Meier, T.: Tracking unilateral earthquake rupture by P-wave polarization analysis, Geophys J Int, 188, 1141-1153, 2012.

Bender, B.: Maximum likelihood estimation of b values for magnitude grouped data, Bull Seismol Soc Am, 73, 831-851, 1983.

Boettcher, M. S., McGarr, A., and Johnston, M.: Extension of Gutenberg-Richter distribution to Mw -1.3, no lower limit in sight, Geophys Res Lett, 36, 2009

Folesky, J., Kummerow, J., and Shapiro, S. A.: Microseismic rupture propagation imaging, Geophysics, 80, WC107-WC115, 2015.

Folesky, J., Kummerow, J., Asch, G., Schurr, B., Sippl, C., Tilmann, F., and Shapiro, S. A.: Estimating rupture directions from local earthquake data using the IPOC observatory in Northern Chile, Seismol Res Lett, 89, 495-502, $2018 \mathrm{a}$.

Folesky, J., Kummerow, J., and Shapiro, S. A.: Estimating rupture directivity of local earthquake data in central Italy using P-wave polarity stacking, in: EGU General Assembly Conference Abstracts, vol. 20, p. 8747, 2018b.

Gay, N. and Ortlepp, W.: Anatomy of a mining-induced fault zone, Geol Soc America Bull, 90, 47-58, 1979.

Gutenberg, B. and Richter, C. F.: Frequency of earthquakes in California, Bull Seismol Soc Am, 34, 185-188, 1944.

Hori, T. and Miyazaki, S.: A possible mechanism of M9 earthquake generation cycles in the area of repeating M7-8 earthquakes surrounded by aseismic sliding, Earth, Planets and Space, 63, 48, 2011.

Ishii, M., Shearer, P. M., Houston, H., and Vidale, J. E.: Extent, duration and speed of the 2004 Sumatra-Andaman earthquake imaged by the Hi-Net array, Nature, 435, 933, 2005.

Ishii, M., Shearer, P., Houston, H., and Vidale, J.: Telseseismic P wave imaging of the 26 December 2004 Sumatra-Andaman and 28 March 2005 Sumatra earthquake ruptures using the Hi-net array, J Geophys Res, 112, 2007.

Kiser, E. and Ishii, M.: The 2010 Mw 8.8 Chile earthquake: Triggering on multiple segments and frequency-dependent rupture behavior, Geophys Res Lett, 38, 2011.

Kiser, E. and Ishii, M.: The March 11, 2011 Tohoku-oki earthquake and cascading failure of the plate interface, Geophys Res Lett, $39,2012$.

Krüger, F. and Ohrnberger, M.: Spatio-temporal source characteristics of the 26 December 2004 Sumatra earthquake as imaged by teleseismic broadband arrays, Geophys Res Lett, 32, 2005.

Kwiatek, G., Plenkers, K., Nakatani, M., Yabe, Y., Dresen, G., et al.: Frequency-magnitude characteristics down to magnitude -4.4 for induced seismicity recorded at Mponeng Gold Mine, South Africa, Bull Seismol Soc Am, 100, 1165-1173, 2010.

Kwiatek, G., Plenkers, K., Dresen, G., and the JAGUARS group: Source parameters of picoseismicity recorded at Mponeng deep gold mine, South Africa: implications for scaling relations, Bull Seismol Soc Am, 101, 2592-2608, 2011. 
https://doi.org/10.5194/se-2020-58

Preprint. Discussion started: 12 May 2020

(c) Author(s) 2020. CC BY 4.0 License.

(c) (i)

Mendecki, A., Van Aswegen, G., and Mountfort, P.: A guide to routine seismic monitoring in mines, A Handbook on Rock Engineering Practice for Tabular Hard Rock Mines, p. 35, 1999.

Mendecki, A. J.: Seismic monitoring in mines, Springer Science \& Business Media, 1996.

Moriya, H., Naoi, M., Nakatani, M., van Aswegen, G., Murakami, O., Kgarume, T., Ward, A. K., Durrheim, R. J., Philipp, J., Yabe, Y., et al.: Delineation of large localized damage structures forming ahead of an active mining front by using advanced acoustic emission mapping techniques, Int J Rock Mech Min Sci, 79, 157-165, 2015.

Moyer, P., Boettcher, M. S., Ellsworth, W. L., Ogasawara, H., Cichowicz, A., Birch, D., and van Aswegen, G.: Call for Models - A Test Case for the Source Inversion Validation: The 2014 ML 5.5 Orkney, South Africa, Earthquake, Seismol Res Lett, 88, $1333-1338,2017$.

Nakatani, M., Yabe, Y., Philipp, J., Morema, G., Stanchits, S., Dresen, G., and the JAGUARS group: Acoustic emission measurements in a deep gold mine in South Africa - - - Project overview and some typical waveforms, Seismol Res Lett, 79, $311,2008$.

Naoi, M., Nakatani, M., Yabe, Y., Kwiatek, G., Igarashi, T., and Plenkers, K.: Twenty thousand aftershocks of a very small (M2) earthquake and their relation to the mainshock rupture and geological structures, Bull Seismol Soc Am, 101, 2399-2407, 2011.

Naoi, M., Nakatani, M., Horiuchi, S., Yabe, Y., Philipp, J., Kgarume, T., Morema, G., Khambule, S., Masakale, T., Ribeiro, L., et al.: Frequency-magnitude distribution of $-3.7<M_{w}<1$ mining-induced earthquakes around a mining front and $\mathrm{b}$ value invariance with postblast time, Pure Appl Geophys, 171, 2665-2684, 2014.

Naoi, M., Nakatani, M., Kgarume, T., Khambule, S., Masakale, T., Ribeiro, L., Philipp, J., Horiuchi, S., Otsuki, K., Miyakawa, K., et al.: Quasi-static slip patch growth to $20 \mathrm{~m}$ on a geological fault inferred from acoustic emissions in a South African gold mine, J Geophys Res, 120, 1692-1707, 2015.

Podvin, P. and Lecomte, I.: Finite difference computation of traveltimes in very contrasted velocity models: a massively parallel approach and its associated tools, Geophys J Int, 105, 271-284, 1991.

Richardson, E. and Jordan, T. H.: Seismicity in deep gold mines of South Africa: Implications for tectonic earthquakes, Bull Seismol Soc Am, 92, 1766-1782, 2002.

Shapiro, S., Krüger, O., Dinske, C., and Langenbruch, C.: Magnitudes of induced earthquakes and geometric scales of fluid-stimulated rock volumes, Geophysics, 76, WC55-WC63, 2011.

Shapiro, S. A.: Fluid-induced seismicity, Cambridge University Press, 2015.

Shapiro, S. A., Krüger, O. S., and Dinske, C.: Probability of inducing given-magnitude earthquakes by perturbing finite volumes of rocks, J Geophys Res, 118, 3557-3575, 2013.

Spottiswoode, S. and McGarr, A.: Source parameters of tremors in a deep-level gold mine, Bull Seismol Soc Am, 65, 93-112, 1975.

Utsu, T.: A statistical significance test of the difference in b-value between two earthquake groups, J Phys Earth, 14, 37-40, 1966.

Van Aswegen, G., Potvin, Y., and Hudyma, M.: Routine seismic hazard assessment in some South African mines, in: Proceedings of 6th International Symposium on Rockburst and Seismicity in Mines, Australian Centre for Geomechanics, Western Australia, 2005.

Voosen, P.: Deep in a mine, earthquake gold awaits, Science, 356, 891-892, 2017.

Wehner, D.: Polarization-based Rupture Directivity Estimation of Earthquakes below Gold Mines in South Africa, Master's thesis, Free University Berlin, Department of Earth Sciences, 2018.

Wehner, D., Folesky, J., Dinske, C., Kummerow, J., and Shapiro, S.: Rupture directivity of earthquakes below gold mines in South Africa, in: 80th EAGE Conference and Exhibition 2018, vol. 2018, pp. 1-3, 2018. 
https://doi.org/10.5194/se-2020-58

Preprint. Discussion started: 12 May 2020

(C) Author(s) 2020. CC BY 4.0 License.

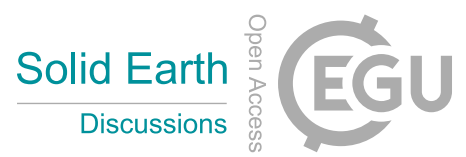

Yabe, Y., Philipp, J., Nakatani, M., Morema, G., Naoi, M., Kawakata, H., Igarashi, T., Dresen, G., Ogasawara, H., et al.: Observation of numerous aftershocks of an $\mathrm{Mw} 1.9$ earthquake with an AE network installed in a deep gold mine in South Africa, Earth, Planets and Space, 61, e49-e52, 2009.

Yabe, Y., Nakatani, M., Naoi, M., Philipp, J., Janssen, C., Watanabe, T., Katsura, T., Kawakata, H., Georg, D., and Ogasawara, H.: Nucleation process of an M2 earthquake in a deep gold mine in South Africa inferred from on-fault foreshock activity, J Geophys Res, 120, 5574 5594, 2015.

300 Ziegler, M., Reiter, K., Heidbach, O., Zang, A., Kwiatek, G., Stromeyer, D., Dahm, T., Dresen, G., and Hofmann, G.: Mining-Induced Stress Transfer and Its Relation to a Mw 1.9 Seismic Event in an Ultra-deep South African Gold Mine, Pure Appl Geophys, 172, 2557-2570, 2015. 
https://doi.org/10.5194/se-2020-58

Preprint. Discussion started: 12 May 2020

(c) Author(s) 2020. CC BY 4.0 License.

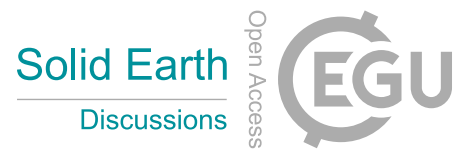

(c) (i)

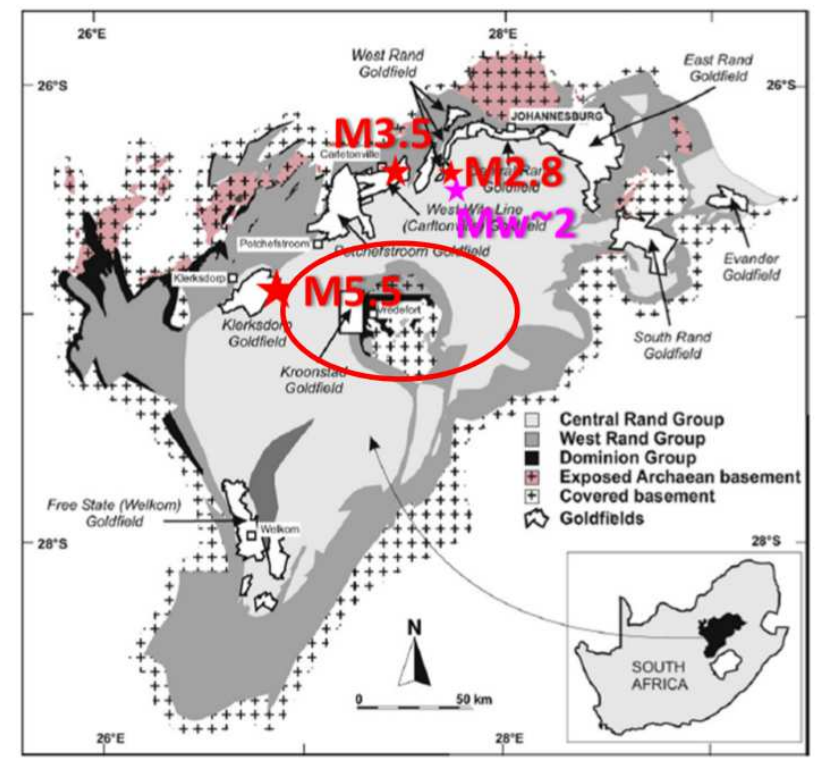

Figure 1. Simplified geological map of the Witwatersrand basin, also showing the locations of gold fields and the locations of the DSeis drilling targets marked in red. 
https://doi.org/10.5194/se-2020-58

Preprint. Discussion started: 12 May 2020

(c) Author(s) 2020. CC BY 4.0 License.

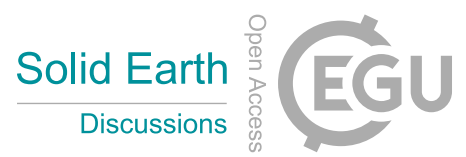

(c) (1)

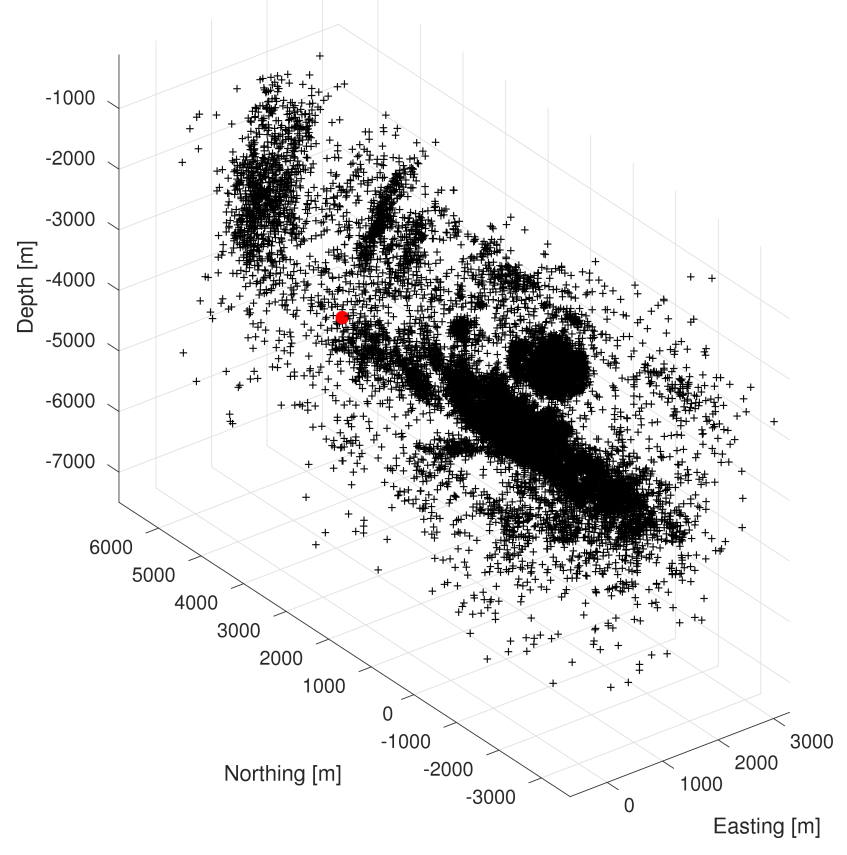

Figure 2. Hypocenter locations of about 70,000 earthquakes in the Orkney area in the DSeis catalog which is derived from the in-mine network. Coordinates are given in meters relative to the location of the Moab Khotsong mine shaft collar $(0 ; 0 ; 1315)$. Red dot marks the hypocenter of the M5.5 earthquake. 
https://doi.org/10.5194/se-2020-58

Preprint. Discussion started: 12 May 2020

(C) Author(s) 2020. CC BY 4.0 License.

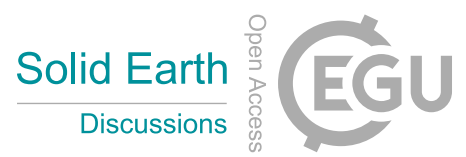

(c) (1)

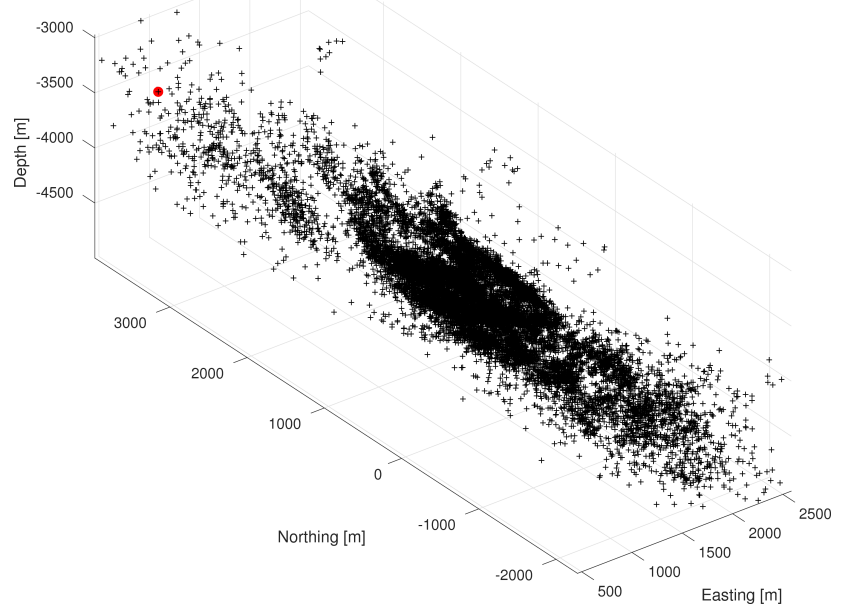

Figure 3. Hypocenter locations of aftershocks of the M5.5 earthquake. Coordinates are given in meters relative to the location of the Moab Khotsong mine shaft collar $(0 ; 0 ; 1315)$. Red dot marks the hypocenter of the M5.5 earthquake. 
https://doi.org/10.5194/se-2020-58

Preprint. Discussion started: 12 May 2020

(c) Author(s) 2020. CC BY 4.0 License.

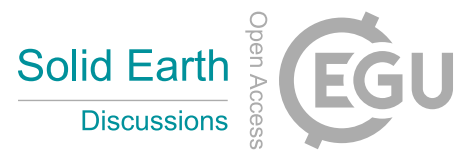

(c) (1)
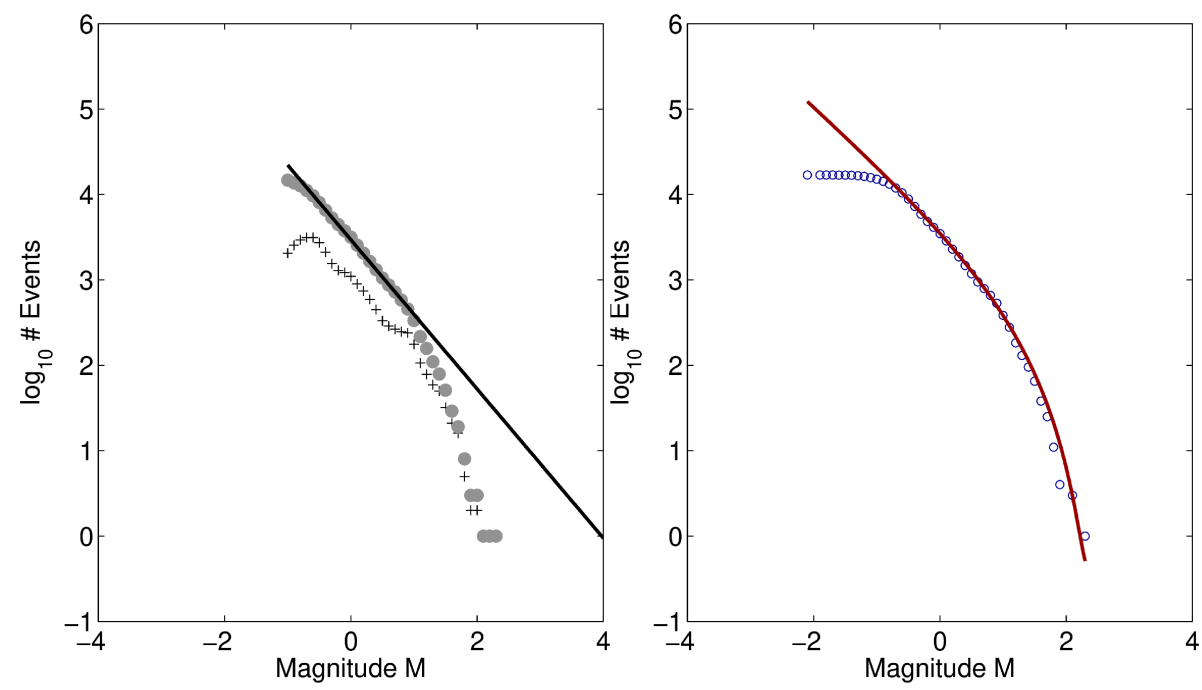

Figure 4. (Left) Magnitude frequency distribution of the aftershock sequence. The $b$ value of the Gutenberg-Richter relation (solid line) was computed using the formula of Bender (1983). (Right) Application of the Lower Bound model (solid line) of magnitude probabilities in finite volume (Shapiro et al., 2013) to the observed magnitude frequencies yields a geometry-corrected $b$ value. 
https://doi.org/10.5194/se-2020-58

Preprint. Discussion started: 12 May 2020

(c) Author(s) 2020. CC BY 4.0 License.

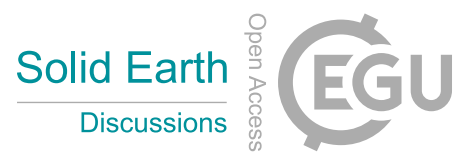

(c) (1)
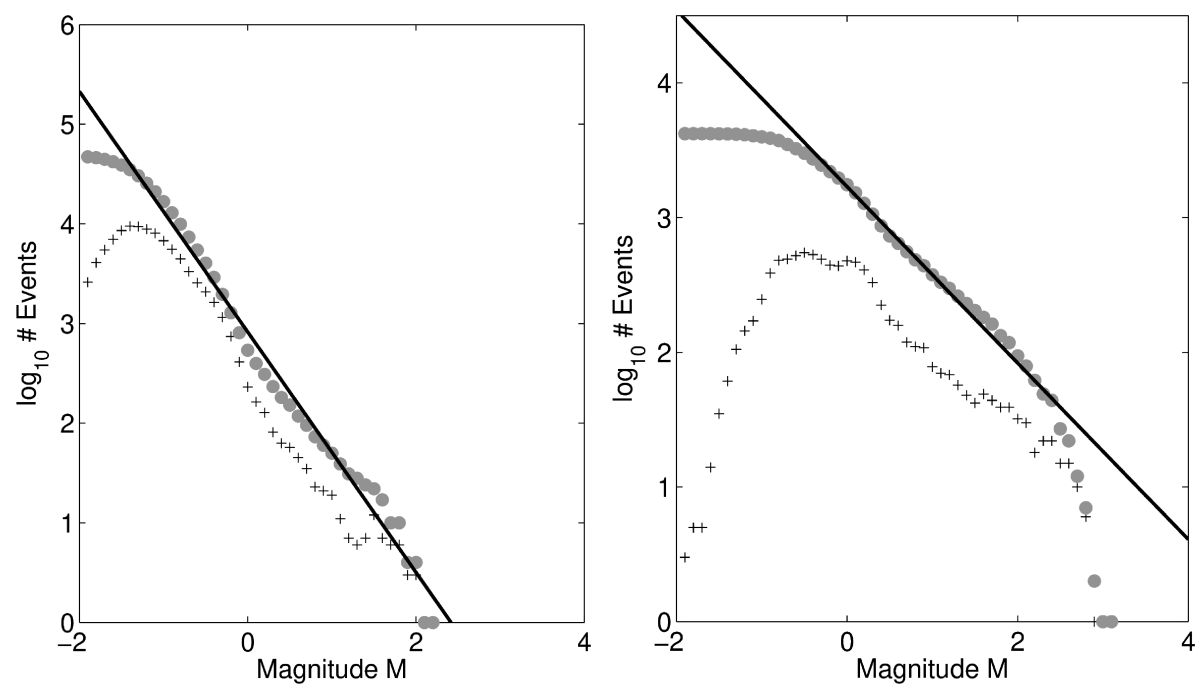

Figure 5. Magnitude frequency distributions of earthquakes induced by human operations in the Orkney area, (left) seismicity induced by fluid, and (right) mining induced seismicity. The $b$ value of the Gutenberg-Richter relation (solid line) was computed using the formula of Bender (1983). 
https://doi.org/10.5194/se-2020-58

Preprint. Discussion started: 12 May 2020

(c) Author(s) 2020. CC BY 4.0 License.

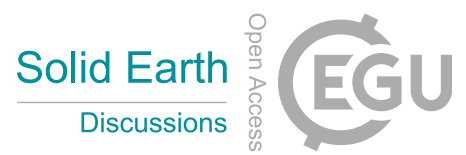

(c) (1)
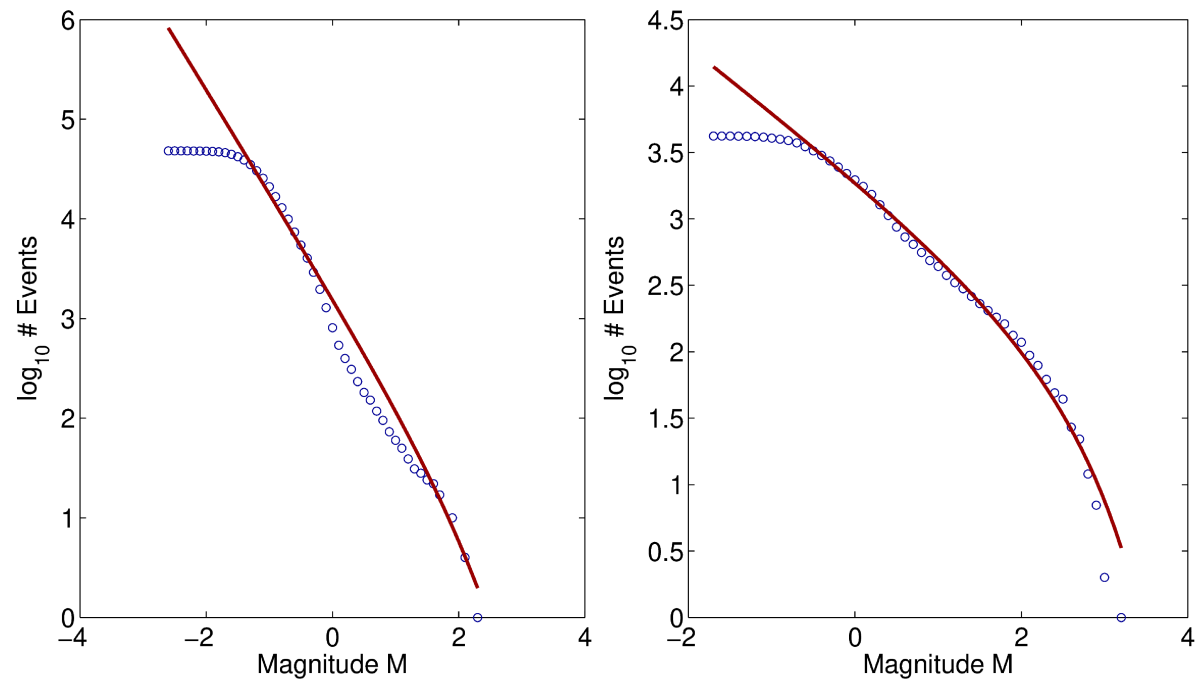

Figure 6. (Application of the Lower Bound model (solid line) of magnitude probabilities in finite volume (Shapiro et al., 2013) to the observed magnitude frequencies yields a geometry-corrected $b$ value. 

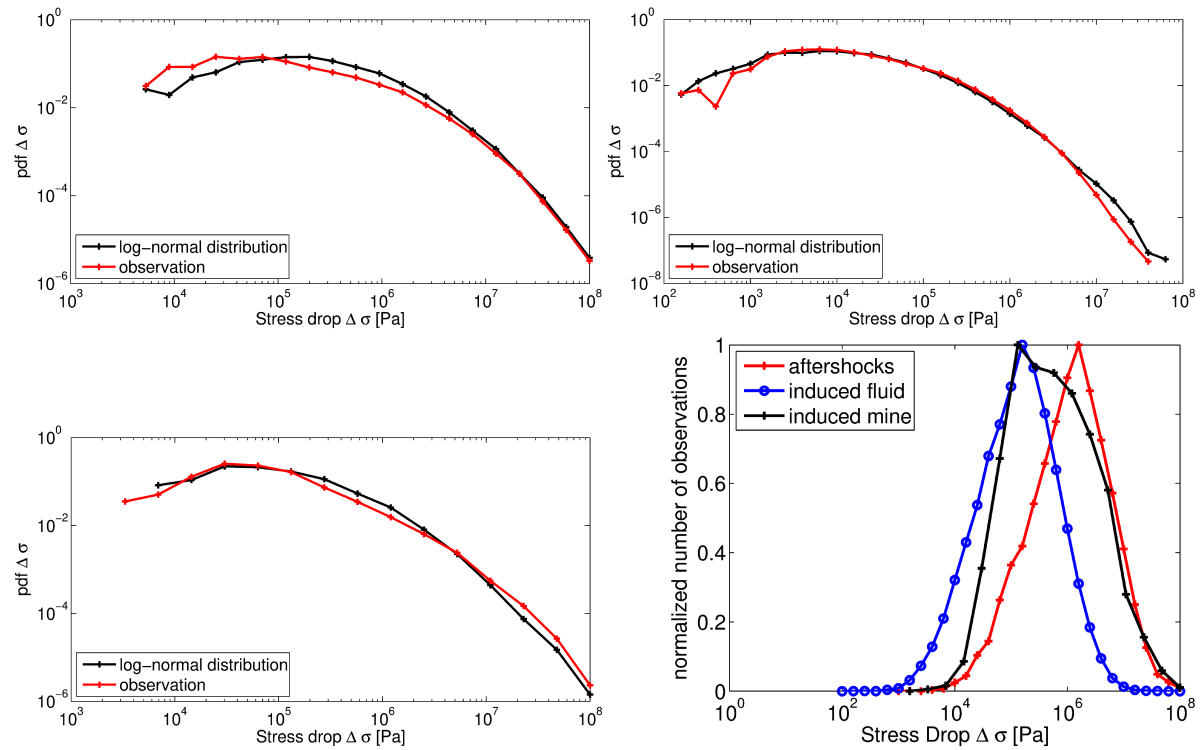

Figure 7. Probability density function of dynamic stress drop of aftershocks (top left), seismicity induced by fluid (top right), and seismicity induced by mining (bottom left), red lines correspond to the observations, black lines are best-fitting log-normal distributions. (Bottom right) Comparison of normalized histograms of dynamic stress drop of earthquakes for the three different classes of seismicity in the Orkney area. 

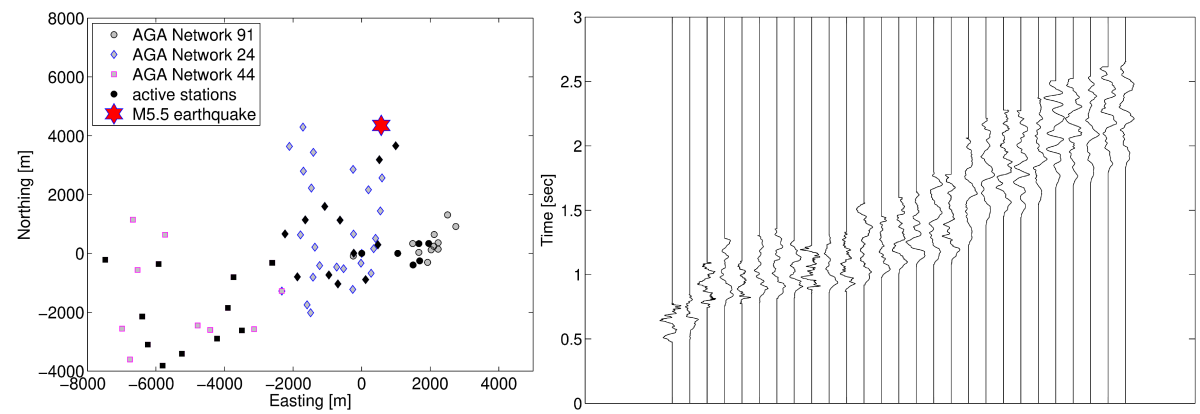

Figure 8. (Left) Map of seismic monitoring stations of the in-mine networks operated by AGA. Coordinates are given in meters relative to the location of the Moab Khotsong mine shaft collar (Longitude $26.802^{\circ}$, Latitude $-26.867^{\circ}$ ). Stations marked in black are used for imaging. (Right) P-wave amplitudes on the vertical component of displacement seismograms from the AGA stations which recorded the main shock. Time $0.0 \mathrm{sec}$ is the inverted origin time of the main shock (10:22:35.10 UTC). 
https://doi.org/10.5194/se-2020-58

Preprint. Discussion started: 12 May 2020

(c) Author(s) 2020. CC BY 4.0 License.

(c) (i)
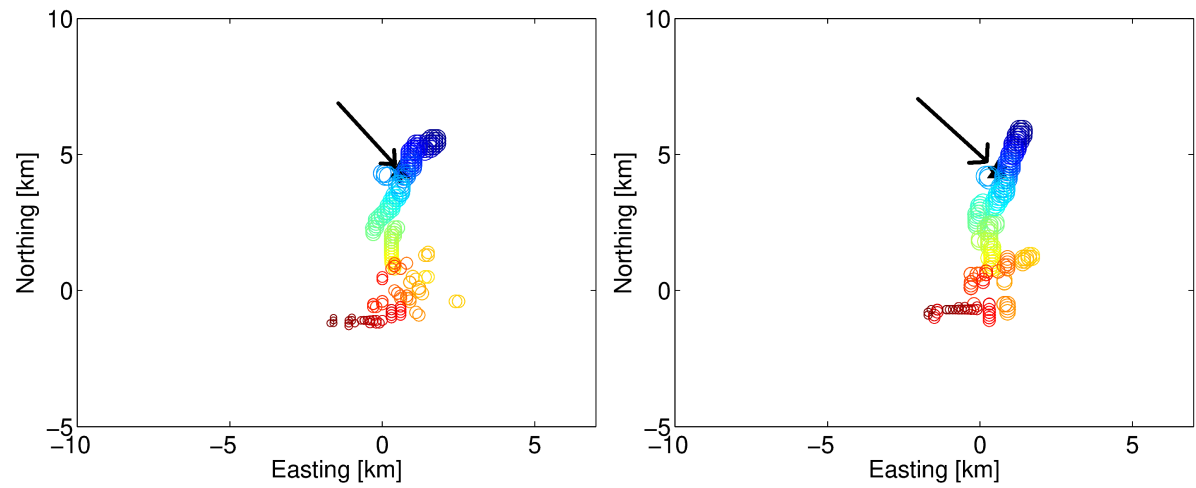

Figure 9. Back projection imaging of the M5.5 rupture using data from the in-mine network, (left) absolute values of P-wave amplitudes and (right) envelopes of P-wave. Coordinates are given in meters relative to the location of the Moab Khotsong mine shaft collar (0;0). The black star (indicated by black arrow) marks the location of the M5.5 earthquake $(0.57 ; 4.35)$. Color (blue - red ) correspond to the time scale from $0-1.5 \mathrm{sec}$. 
https://doi.org/10.5194/se-2020-58

Preprint. Discussion started: 12 May 2020

(C) Author(s) 2020. CC BY 4.0 License.

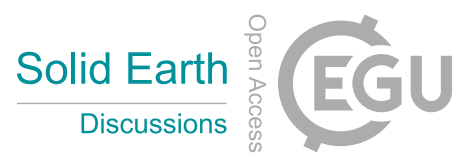

(c) (i)
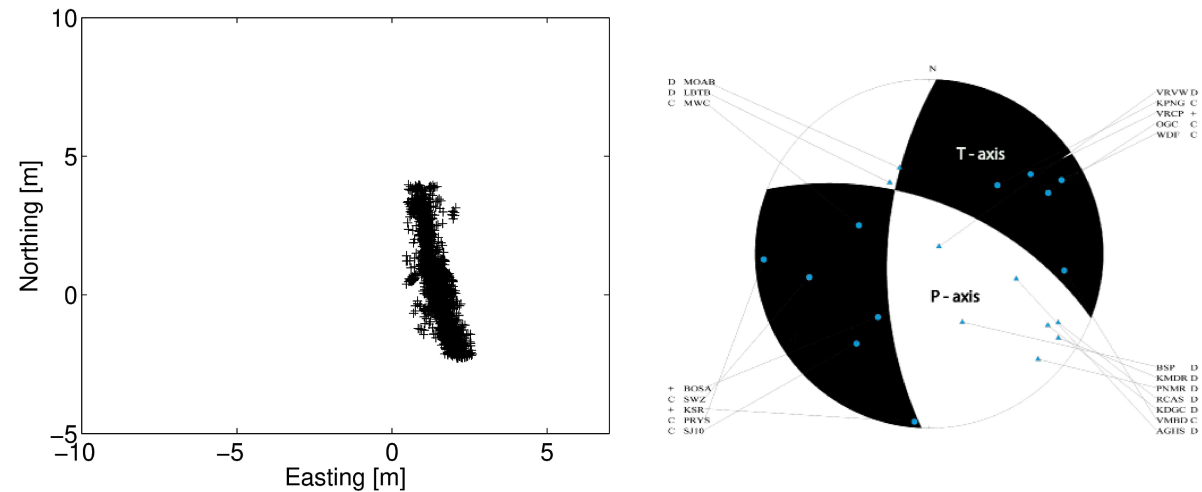

Figure 10. (Left) Map view of locations of the cloud of aftershocks for comparing with the MRPI results illustrated in Figure 9. (Right) Focal mechanism solution of one of the aftershocks which is representative for the M5.5 Orkney earthquake (see also Table 1 in Manzunzu et al., 2017). 
https://doi.org/10.5194/se-2020-58

Preprint. Discussion started: 12 May 2020

(c) Author(s) 2020. CC BY 4.0 License.
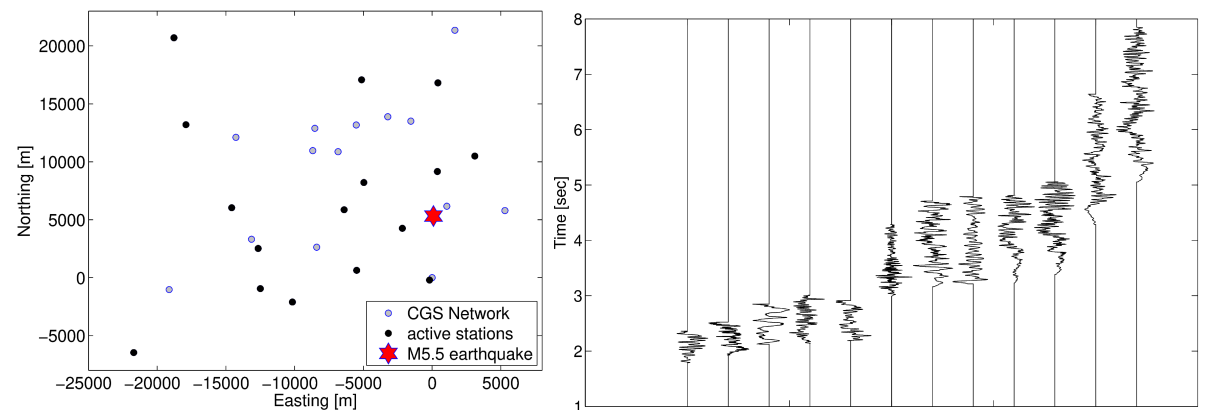

Figure 11. (Left) Map of seismic monitoring stations of the surface network operated by CGS. Coordinates are given in meters relative to the location of the Moab Khotsong mine shaft collar (Longitude $26.802^{\circ}$, Latitude $-26.867^{\circ}$ ). Stations marked in black are used for imaging. (Right) P-wave amplitude on the vertical component of displacement seismograms from the CGS stations which recorded the main shock. Time $0.0 \mathrm{sec}$ is the inverted origin time of the main shock (10:22:34.75 UTC). 
https://doi.org/10.5194/se-2020-58

Preprint. Discussion started: 12 May 2020

(c) Author(s) 2020. CC BY 4.0 License.

(c) (i)
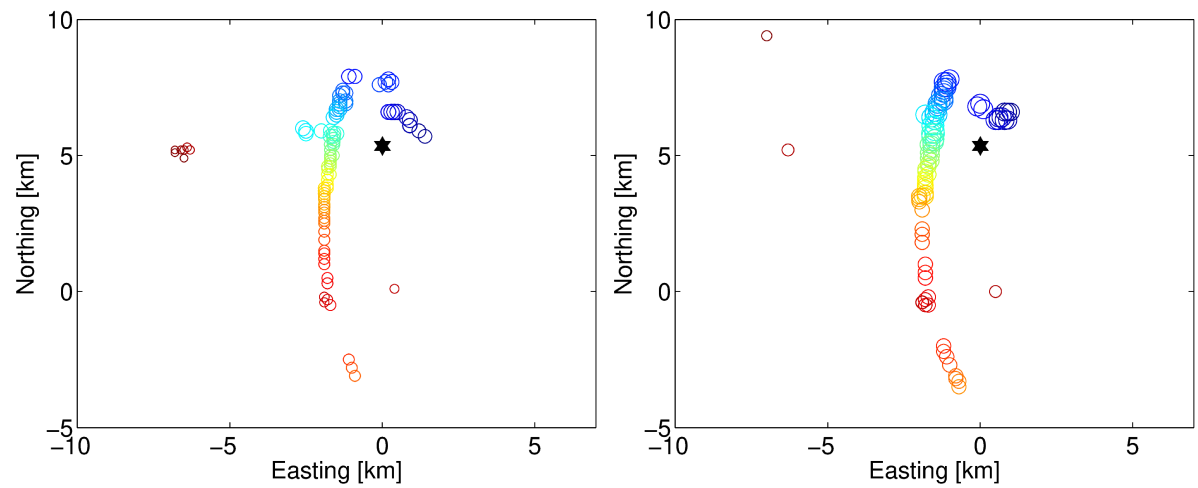

Figure 12. Back projection imaging of the M5.5 rupture using data from the surface network, (left) absolute values of P-wave amplitudes and in (right) envelopes of P-wave. Coordinates are given in meters relative to the location of the Moab Khotsong mine shaft collar $(0 ; 0)$. The black star marks the location of the M5.5 earthquake (0.1;5.3). Color (blue - red ) correspond to the time scale from 0-1.5 sec. 
https://doi.org/10.5194/se-2020-58

Preprint. Discussion started: 12 May 2020

(c) Author(s) 2020. CC BY 4.0 License.

Table 1. Summary of retrieved parameters of the magnitude statistics of seismicity in the Orkney area.

\begin{tabular}{|l|c|c|c|}
\hline & aftershock sequence & fluid induced & mining induced \\
\hline completeness magnitude $M_{c}$ & -0.6 & -0.5 & -0.4 \\
maximum likelihood $b$-value & 0.84 & 0.96 & 0.61 \\
Lower Bound $b$-value & 0.73 & 1.08 & 0.52 \\
Lower Bound $M_{\max }$ & 2.4 & 3.3 & 3.8 \\
\hline Lower Bound stress drop $\Delta \sigma$ & $700 \mathrm{kPa}$ & $140 \mathrm{kPa}$ & $500 \mathrm{kPa}$ \\
median of static stress drops & $420 \mathrm{kPa}$ & $40 \mathrm{kPa}$ & $80 \mathrm{kPa}$ \\
median of dynamic stress drops & $950 \mathrm{kPa}$ & $120 \mathrm{kPa}$ & $340 \mathrm{kPa}$ \\
\hline
\end{tabular}


https://doi.org/10.5194/se-2020-58

Preprint. Discussion started: 12 May 2020

(C) Author(s) 2020. CC BY 4.0 License.

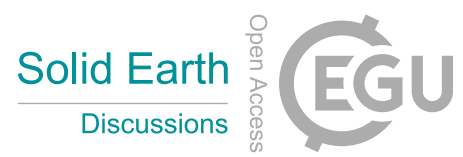

(c) (1)

Table 2. Velocity model used in NonLinLoc to locate the M5.5 earthquake and to compute the traveltime-grid for MRPI using the CGS waveform data (a.s.l. - above sea level, b.s.l. - below sea level).

\begin{tabular}{|c|c|c|c|}
\hline layer & top of layer & P-wave velocity $v_{P}$ & S-wave velocity $v_{S}$ \\
\hline 1 & $200 \mathrm{~m}$ a.s.1. & $3.79 \mathrm{~km} / \mathrm{s}$ & $2.39 \mathrm{~km} / \mathrm{s}$ \\
2 & $800 \mathrm{~m}$ b.s.l. & $5.96 \mathrm{~km} / \mathrm{s}$ & $3.61 \mathrm{~km} / \mathrm{s}$ \\
\hline
\end{tabular}

